Research Paper

\title{
Metabolite profiling of Schizochytrium sp. by GC-MS, an oleaginous microbial source of biodiesel
}

\author{
Roberto Mioso $^{1}$, Francisco J. Toledo Marante ${ }^{1}$, Juan E.G. González², \\ Juan J. S. Rodríguez ${ }^{2}$, Irma Herrera Bravo de Laguna ${ }^{1}$ \\ ${ }^{1}$ Departamento de Química, Universidad de Las Palmas de Gran Canaria, Gran Canaria, Spain. \\ ${ }^{2}$ Departamento de Ingeniería de Procesos, Universidad de Las Palmas de Gran Canaria, \\ Gran Canaria, Spain.
}

Submitted: November 20, 2012; Approved: September 9, 2013.

\begin{abstract}
The chemical screening carried out on Schizochytrium sp. biomass led the identification of 24 types of organic compounds belonging to $n$-alkanes, 1 -alkenes, 1 -alkanols, free fatty acids, methyl and ethyl esters of saturated and unsaturated fatty acids, saturated tri- and diglycerides, unsaturated monoglycerides, wax esters, sterols, triterpenes, and mono- and sesquiterpenes. Moreover, a sample containing fully saturated ethyl biodiesel was obtained experimentally with a yield of $28.72 \% \mathrm{w} / \mathrm{w}$ of the crude extract, and an average chain length of 15.52 carbons. This strain produced no toxins, but showed important nutrients, making it potentially applicable to the field of functional food, and biodiesel production.
\end{abstract}

Key words: Schizochytrium sp., zoosporic microorganism, organic compounds, renewable fuel.

\section{Introduction}

Schizochytrium sp. is a zoosporic organism that belongs to the Labyrinthulomycota Phylum, a known group of protists abundant in marine and estuarine environment (Porter, 1990). In the last decades, a particular attention has been given to this group of organisms, since it has been proven to be a very productive source of important primary metabolites of industrial interest (Yongmanitchai and Ward, 1989). These organisms are capable to produce, by de novo synthesis, both saturated and unsaturated fatty acids, particularly long chain polyunsaturated fatty acids from non-lipid conventional sources (Bowles et al., 1999; Yokochi et al., 1998).

Its importance has increased due to the growing demand for these marine natural products, potentially capable of generating commercial applications in nutraceutical, pharmaceutical and aquaculture (Lewis et al., 1999, 2000; Nichols et al., 1999). Beyond the role outlined to these lipids, Schizochytrium sp. can be similarly an interesting producer of secondary metabolites. So that, although their fatty acid profiles have been described (Ashford et al.,
2000; Barclay and Zeller, 1996), the bibliographic background indicate the presence of glycolipids, phospholipids, sphingolipids and sterols as cholesterol, stigmasterol and brassicasterol (Kendrick and Ratledge, 1992).

Furthermore, these organisms also become of industrial interest as a biodiesel source. Biodiesel, as an alternative fuel, has attracted increasing worldwide attention driven by factors such as oil price spikes, the need for increased energy security, and concern over greenhouse gas emissions from fossil fuels (Bondioli et al., 2008). Oleaginous fermentations from microbial strains can generate high added-value biodiesel by using a large variety of material as glycerol and ethanol as a carbon source to produce single-cell biomass (Johnson and Takoni, 2007; OchoaEstopiera et al., 2011).

The present work reports the study of the metabolites biosynthesized by the heterotrophic Schizochytrium sp. which was produced by fermentation, in accordance with Barclay procedures (Barclay, 1994). It was carried out a detailed screening of its lipo- and hydrosoluble fractions, and its compounds were identified by GC-MS and NMR spectroscopy, looking for to confirm those substances described

Send correspondence to I.Herrera Bravo de Laguna. Departamento de Química, Universidad de Las Palmas de Gran Canaria, Campus Universitario de Tafira, Edificio de Ciencias Básicas, 35017 Las Palmas de Gran Canaria, Gran Canaria, Spain. E-mail: irmagallotia@hotmail.com. 
previously in the literature and isolate new structures that could show any interesting bioactivity, as well as, provide some type of industrial application as a biodiesel production, for instance.

\section{Materials and Methods}

\section{Microorganism and heterotrophic production}

The heterotrophic Schizochytrium sp. was purchased from Aquafauna Bio-Marine Inc., Hawthorne, CA, USA. The biomass fermentation was produced by Omega Tech Inc., Bounder, $\mathrm{CO}$, USA, in accordance with Barclay procedures (Barclay, 1994). The biomass obtained was concentrate by centrifugation, spray-dried and vacuum packaging (Barclay and Zeller, 1996).

\section{Obtaining of the extract and fractionation procedure}

A sample of $110 \mathrm{~g}$ of spray-dried Schizochytrium sp. was soaked in dichloromethane $(\mathrm{x} 3,24 \mathrm{~h})$ and methanol (x3, $24 \mathrm{~h})$. The extracts were filtered by Whatman paper (grade 1) and evaporated at reduced pressure in a rotary evaporator. Thus, they were combined, dried under high vacuum, and stored in the fridge under a nitrogen atmosphere. The resulting crude extract was, then, subjected to partition by polarity in accordance to a modified Kupchan solvent partitioning scheme (Kupchan et al., 1973). See Figure S1, in the supplementary material.

\section{Experimental}

Normal-phase column chromatography was carried out on silica gel (Scharlau) with a $0.06-0.2 \mathrm{~mm}$ particle size as the adsorbent in the head of the chromatographic column and $0.04-0.06 \mathrm{~mm}$ for the stationary phase. The chromatography was performed either a medium pressure (Büchi Chromatography System) or a low pressure with a Fluid Metering Inc. motors connected in series with an Ace Glass Inc. column. Reverse-phase chromatography was achieved on LiChroprep RP-18 (Merck, 40-63 $\mu \mathrm{m}$ particle size) column connected with a low pressure chromatography system based in a Fluid Metering Inc. apparatus too. Size exclusion chromatography was carried out on lipophilic Sephadex ${ }^{\circledR}$ LH-20 (Sigma). The column was conditioned first with anhydrous methanol $(2 \mathrm{~h})$ and then with a mixture of $\mathrm{CH}_{2} \mathrm{Cl}_{2} / \mathrm{CH}_{3} \mathrm{OH}(50: 50,2 \mathrm{~h})$. The extracts were applied on the top of the column and eluted with $\mathrm{CH}_{2} \mathrm{Cl}_{2} / \mathrm{CH}_{3} \mathrm{OH}$ $(50: 50)$ at a rate of $1.0 \mathrm{~mL} \mathrm{~min}^{-1}$. Normal-phase TLC was performed on silica gel plates $(0.25 \mathrm{~mm}$ diameter, Tracer Analitica) using a combination of hexane, ethyl acetate, chloroform and methanol as eluent, at the proportion detailed in each case. Reverse-phase TLC was carried out on $\mathrm{RP}-18 \mathrm{~F}_{254}$ plates $(0.25 \mathrm{~mm}$ diameter, Merck) with the use of $\mathrm{CH}_{3} \mathrm{CN} / \mathrm{CH}_{3} \mathrm{OH} / \mathrm{H}_{2} \mathrm{O}(80: 18: 2)$ as a mobile phase. In all cases, the TLC spots were revealed by spraying with oleum (sulphuric acid, $4 \%+$ acetic acid, $80 \%+$ water, $16 \%$ ) and heating at $120{ }^{\circ} \mathrm{C}$ for $20 \mathrm{~min}$. Normal-phase semi-prepa- rative HPLC were performed on an Alltech Econosphere C1 8 column $(10 \mu \mathrm{m}$ particle size, 250 x $4.6 \mathrm{~mm}, 100 \AA$ pore size) and reverse-phase semi-preparative HPLC were performed on a Waters ODS column (10 $\mu \mathrm{m}$ particle size, 250 x $4.6 \mathrm{~mm}, 100 \AA$ pore size). Both of them, were carried out on a semi-preparative HPLC apparatus accomplished to Spectra-physics P100 isocratic pump and used in line with a Hewlett Packard 1050 UV-VIS variable wavelength detector, working at room temperature $\left(26{ }^{\circ} \mathrm{C}\right)$ and at $\lambda=254 \mathrm{~nm}$. Analytical Chromatography was performed using a Shimadzu HPLC system with a LC-9A pump connected in line with a UV-VIS SPD-6AV detector $(\lambda=254 \mathrm{~nm})$. The conditions used for the normal-phase analytical chromatography were combinations of hexane and ethyl acetate as eluent and for the size-exclusion chromatography column (Shodex OH Pak SB 806 HQ) were used a mixture of water and $0.05 \%$ of sodium azide as eluent. An eluent flow rate of $1.0 \mathrm{~mL} \mathrm{~min}{ }^{-1}$ was used in all analysis. ${ }^{1} \mathrm{H}$ - and ${ }^{13} \mathrm{C}$-NMR spectroscopy experiments were recorded at 250 or $300 \mathrm{MHz}$ on $\mathrm{AC}$ or AMX Bruker apparatus, respectively. Tetramethylsilane was used as an internal standard for ${ }^{1} \mathrm{H}$ and deuterated chloroform $(\delta 77.00)$ or deuterated methanol $(\delta 49.00)$ for the calibration of the ${ }^{13} \mathrm{C}-\mathrm{NMR}$ spectra. Gas chromatography-mass spectrometry (GC-MS) analysis was carried out on a chromatograph model Varian CP3800 with an ion-trap mass spectrometer model Saturn 2000 and under the following conditions: CP-Sil 8 low bleed capillary column. The injector temperature was kept isothermal at $270{ }^{\circ} \mathrm{C}$; initial split conditions on; $0.01 \mathrm{~min}$ off and $5 \mathrm{~min}$ on with a split ratio 1:50; the oven was set at $50{ }^{\circ} \mathrm{C}$ for $5 \mathrm{~min}$, and then ramped at $15^{\circ} \mathrm{C} \mathrm{min}^{-1}$ till $250^{\circ} \mathrm{C}$ and held for $10 \mathrm{~min}$ (total run time of $28.33 \mathrm{~min}$ for each sample); flux of $1 \mathrm{~mL} \mathrm{~min}^{-1}$; mass detector in the EI mode (the $\mathrm{m} / \mathrm{z}$ range was 20 to 400 ). Relative $\mathrm{GC}$ retention times were obtained by comparison of authentic standard alkanes (Dr. Ehrenstorfer GmbH Alkanes-Mix 10), fatty acid methyl esters (Supelco ${ }^{\circledR}$ 37-Component FAME Mix), 1-alkenes and 1-alkanols (Chemika Fluka). The rest were assigned by similarity of the MS footprint observed with the registered ones in the NIST library.

\section{Results and Discussion}

\section{Chemical analysis of the microbial biomass}

After extracting the microbial biomass and partitioned it in accordance to Figure S1 (see the supplementary material), all fractions were screened carefully by GC-MS for their volatile components as well by refractionation: TLC, column chromatography, size-exclusion chromatography and spectroscopic study (NMR), identifying the following substances: 


\section{Organic compounds}

Organic compounds were identified by GC-MS (Table 1) and classified by structural criteria (Figures 1 and 2), as following: $n$-alkanes (1), 1-alkenes (5), 1-alkanols (2), saturated (3) and unsaturated (7) free fatty acids, saturated $(4,6)$ and unsaturated $(8,9,10)$ methyl and ethyl esters of fatty acids, saturated triglycerides (12) and diglycerides $(13,14)$, unsaturated monoglycerides (15), wax esters (16),

Table 1. Organic compounds identified in the biomass of Schizochytrium sp. by GC-MS.

\begin{tabular}{|c|c|c|}
\hline No & Retention time min $($ mean $\pm \mathrm{SD})$ & Compound (structure) \\
\hline 1 & $12.377 \pm 0.009$ & Tridecane $(\mathbf{1} ; \mathrm{n}=10)$ \\
\hline 2 & 12.484 & 2H-Pyran-2-one, tetrahydro-4-hydroxy-4-methyl- (17) \\
\hline 3 & 12.789 & Cyclohexanol, 2-methyl-5-(1-methylethyl)-, $(1 \alpha, 2 \beta, 5 \beta)-(19)$ \\
\hline 4 & 12.803 & 4-Hydroxy-3,4,6-trimethylhept-5-enoic acid lactone (20) \\
\hline 5 & $12.837 \pm 0.009$ & Cyclohexanol, 4-methyl-1-(1-methylethyl)- (18) \\
\hline 6 & $13.230 \pm 0.006$ & 1-Pentadecene $(\mathbf{5} ; \mathrm{n}=12)$ \\
\hline 7 & $13.287 \pm 0.012$ & Tetradecane $(\mathbf{1} ; \mathrm{n}=11)$ \\
\hline 8 & $14.145 \pm 0.012$ & Pentadecane $(\mathbf{1} ; \mathrm{n}=12)$ \\
\hline 9 & 14.260 & Trinonanoin $(12 ; \mathrm{n}=7)$ \\
\hline 10 & $14.396 \pm 0.053$ & Dodecanoic acid, methyl ester $(4 ; \mathrm{n}=10)$ \\
\hline 11 & 14.412 & Undecanoic acid, 10-methyl-, methyl ester $(\mathbf{1 1} ; \mathrm{n}=8)$ \\
\hline 12 & 14.590 & Stearic acid, 1,2,3-propanetriyl ester $(\mathbf{1 2} ; \mathrm{n}=16)$ \\
\hline 13 & $14.812 \pm 0.066$ & Tetradecanoic acid $(\mathbf{3} ; \mathrm{n}=12)$ \\
\hline 14 & $14.875 \pm 0.024$ & 1-Hexadecene $(\mathbf{5} ; \mathrm{n}=13)$ \\
\hline 15 & 14.885 & Dodecanoic acid, ethyl ester $(\mathbf{6} ; \mathrm{n}=10)$ \\
\hline 16 & 15.128 & Tridecanoic acid, methyl ester $(4 ; n=11)$ \\
\hline 17 & 15.609 & 9-Hexadecenoic acid, tetradecyl ester, $(\mathrm{Z})-(\mathbf{1 6} ; \mathrm{n}=13)$ \\
\hline 18 & 15.632 & Tridecanoic acid, ethyl ester $(\mathbf{6} ; \mathrm{n}=11)$ \\
\hline 19 & 15.672 & Stigmasterol (23) \\
\hline 20 & $15.924 \pm 0.055$ & Methyl tetradecanoate $(4 ; \mathrm{n}=12)$ \\
\hline 21 & $16.316 \pm 0.089$ & Hexadecanoic acid $(3 ; \mathrm{n}=14)$ \\
\hline 22 & 16.330 & 1-Eicosanol (2) \\
\hline 23 & $16.378 \pm 0.046$ & Tetradecanoic acid, ethyl ester $(\mathbf{6} ; \mathrm{n}=12)$ \\
\hline 24 & 16.388 & 1-Octadecene $(\mathbf{5} ; \mathrm{n}=15)$ \\
\hline 25 & $16.403 \pm 0.072$ & 7-Tetradecenoic acid, $(\mathrm{Z})-(7 ; \mathrm{n}=5, \mathrm{~m}=5)$ \\
\hline 26 & $16.629 \pm 0.036$ & Pentadecanoic acid, methyl ester $(4 ; n=13)$ \\
\hline 27 & $17.071 \pm 0.026$ & Pentadecanoic acid, ethyl ester $(\mathbf{6} ; \mathrm{n}=13)$ \\
\hline 28 & $17.193 \pm 0.053$ & 9-Hexadecenoic acid, methyl ester, $(\mathrm{Z})-(\mathbf{8} ; \mathrm{n}=5, \mathrm{~m}=7)$ \\
\hline 29 & $17.303 \pm 0.044$ & Hexadecanoic acid, methyl ester $(4 ; n=14)$ \\
\hline 30 & $17.311 \pm 0.044$ & Pentadecanoic acid, 14-methyl-, methyl ester $(\mathbf{1 1} ; \mathrm{n}=12)$ \\
\hline 31 & 17.427 & Germanicol (24) \\
\hline 32 & $17.607 \pm 0.037$ & Ethyl 9-hexadecenoate $(\boldsymbol{9} ; \mathrm{n}=5, \mathrm{~m}=7)$ \\
\hline 33 & $17.702 \pm 0.044$ & Hexadecanoic acid, ethyl ester $(\mathbf{6} ; n=14)$ \\
\hline 34 & 17.735 & Octadecanoic acid, 2-hydroxy-1,3-propanediyl ester (13) \\
\hline 35 & $17.735 \pm 0.179$ & Hexadecanoic acid, 1-(hydroxymethyl)-1,2-ethanediyl ester (14) \\
\hline 36 & 17.904 & Heptadecanoic acid, methyl ester $(4 ; n=15)$ \\
\hline 37 & 18.413 & 9,12-Octadecadienoic acid (Z,Z)-, methyl ester (10) \\
\hline 38 & 18.416 & 9-Octadecenoic acid, methyl ester $(\mathbf{8} ; \mathrm{n}=7, \mathrm{~m}=7)$ \\
\hline 39 & $18.459 \pm 0.046$ & 9-Octadecenoic acid (Z)-, 2-hydroxy-1-(hydroxymethyl)ethyl ester (15) \\
\hline 40 & 18.514 & 11-Octadecenoic acid, methyl ester, $(Z)-(\mathbf{8} ; \mathrm{n}=5, \mathrm{~m}=9)$ \\
\hline 41 & 18.533 & Octadecanoic acid, methyl ester $(4 ; n=16)$ \\
\hline 42 & 18.764 & 9-Hexadecenoic acid, eicosyl ester, $(Z)-(\mathbf{1 6} ; n=19)$ \\
\hline 43 & 18.838 & Ethyl 9-octadecenoate $(\mathrm{Z})-(\mathbf{9} ; \mathrm{n}=7, \mathrm{~m}=7)$ \\
\hline 44 & 18.870 & Cholesterol (22) \\
\hline 45 & 18.954 & Octadecanoic acid, ethyl ester $(6 ; n=16)$ \\
\hline 46 & 19.038 & 1-Dodecanol, 3,7,11-trimethyl- (21) \\
\hline 47 & 19.206 & Docosanoic acid, 1,2,3-propanetriyl ester $(\mathbf{1 2} ; \mathrm{n}=20)$ \\
\hline 48 & 19.775 & Erucic acid $(7 ; n=7, m=11)$ \\
\hline 49 & 20.024 & Eicosanoic acid, methyl ester $(4 ; n=18)$ \\
\hline
\end{tabular}




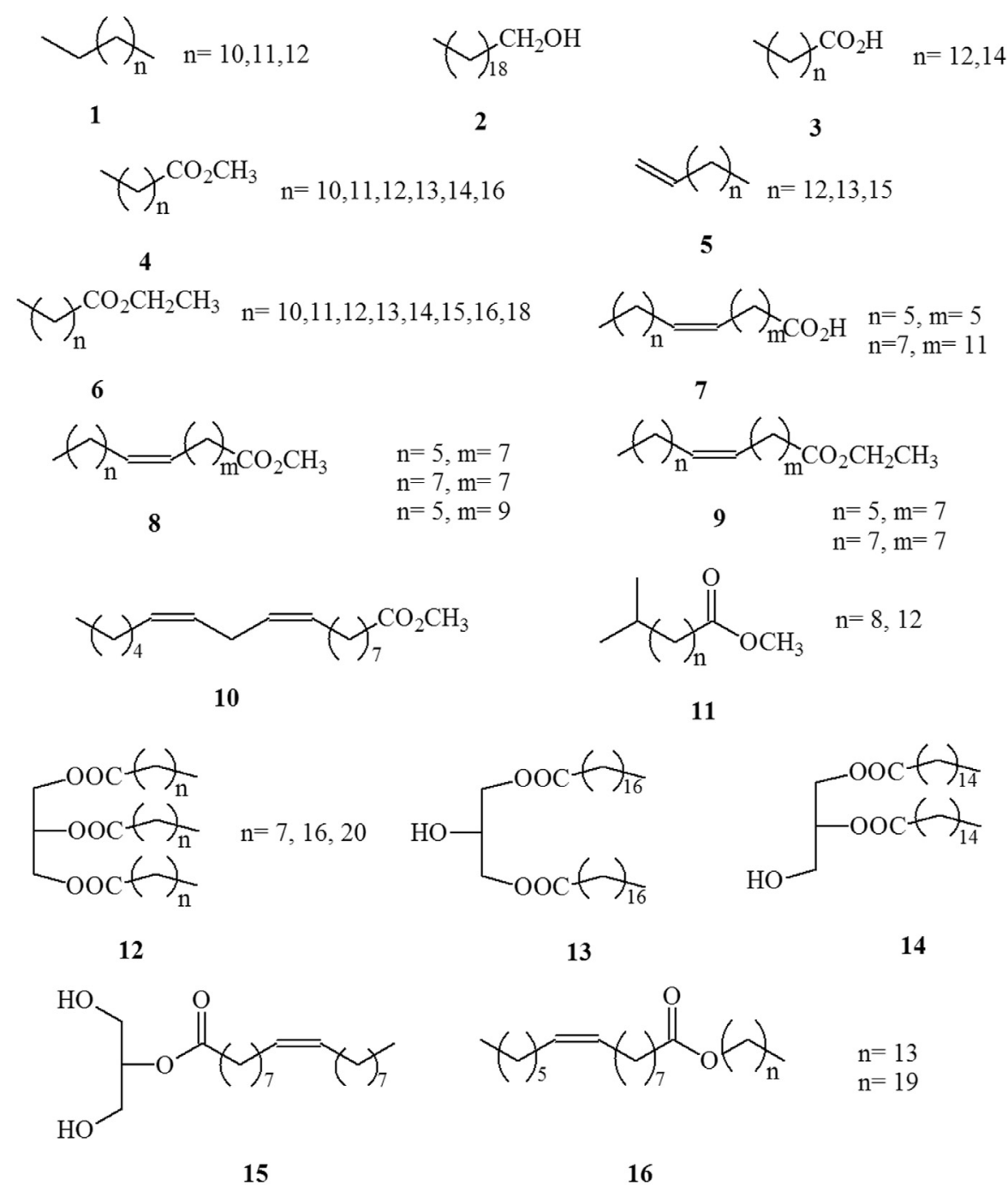

Figure 1 - Lipid compounds identified in Schizochytrium sp.

sterols $(22,23)$, triterpenes (24), mono- and sesquiterpenes $(17-21)$.

\section{Occurrence of branched fatty acid methyl esters}

The methyl-branched fatty acids are widely distributed in the nature (Carballeira et al., 2001; Nechev et al., 2002). Now is known, that they are formed by the selective incorporation of the methylmalonyl-CoA, catalysed by the fatty acid synthetase enzyme (Seyama et al., 1981), and that such bioenergetic pathway is characteristic from bacteria that produce relative high concentrations of these isomethylbranched fatty acids. Which are, therefore, accepted as molecular markers of the organic matter produced by bacteria (Kaneda, 1991; Zabeti et al., 2010). Therefore, the identification of the 10-methyundecanoic acid $(11, \mathrm{n}=8)$ and the 14-methylpentadecanoic acid $(11, \mathrm{n}=12)$ methyl esters, two derivatives from iso-methylbranched fatty acids, is an indirect evidence of the presence of Mycobacterium genus associated to Schizochytrium sp. biomass.
Apart of its GC-MS fingerprint, the iso-methyl-substitution proposed in 11 was confirmed by relatively intense fragment ion peak at $\mathrm{M}^{+}-43$ observed by GC-MS together to the intensity diminution of the $\mathrm{M}^{+}-29$ fragment (Andersson, 1978).

\section{Absence of toxins}

Although there are few studies on the chemistry of this organism is widely accepted that different metabolite profiles can result from each strain and, also, through of different fermentation conditions (Wang et al., 1998). However, and under the present methodology applied, it was unsuccessful to find in the biomass possible toxics bioactive compounds harmful to humans or animals. Or, even, intermediary metabolites involved in a biogenetic pathway that could give rise to these substances. This suggests the potential use of this strain for food purposes, both animal and human. 
<smiles>CC1(O)CCOC(=O)C1</smiles>

17<smiles>CC(C)CCC(C)(C)CC(C)CCC(C)CCO</smiles>

21

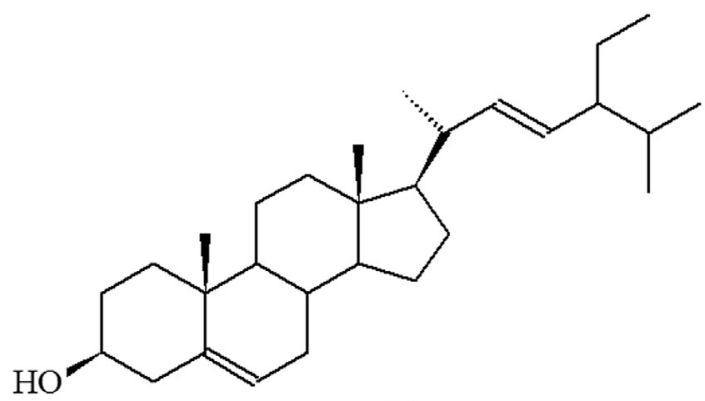

23

Figure 2 - Terpenoids identified in Schizochytrium sp.

\section{Biodiesel production by transesterification of saturated esters}

Lipid accumulation from oleaginous microorganisms is under investigation as an alternative to the use of food crop and oils plant as feedstock for the obtaining of renewable fuels and chemicals (Nigam and Singh, 2011). Fungi are especially of interest since they convert efficiently non lipid sources, as the use crop residues or industrial byproduct, in cellular lipids. Thus, in order to provide data that could supply a reference to the applicability of Schizochytrium sp. in the manufacture of biodiesel, dried-cells were extracted with solvents to obtain a crude extract $(15.77 \% \mathrm{w} / \mathrm{w})$ which was submitted to column chromatography. Monitoring by TLC allowed a total of six fractions. The fourth was taken by the majority $(68.69 \%$ w/w with respect to crude extract) and ${ }^{1} \mathrm{H}-\mathrm{NMR}$ spectroscopy was made up mostly of triglycerides of saturated fatty acids. Transesterification with ethanol followed by column chromatography purification led to a sample of abundant saturated ethyl biodiesel $(41.60 \% \mathrm{w} / \mathrm{w}$ compared to crude extract). Integral curve of ${ }^{1} \mathrm{H}-\mathrm{NMR}$ spectrum (Figure 3) followed a chain length average of 15.52 carbons. In this experiment it was showed that Schizochytrium sp., which<smiles>CC(C)[C@H]1C[C@H](C)[C@@H](O)C[C@H]1C</smiles>

19

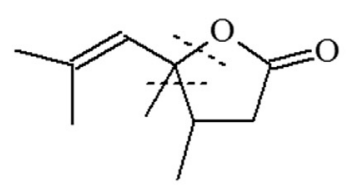

20<smiles>CC(C)CCC[C@H](C)[C@H]1CCC2C3CC=C4CC(O)CC[C@]4(C)C3CC[C@]21C</smiles>

22
24

was produced by fermentation and in accordance to Barclay procedures (Barclay, 1994), can be used to produce good yields of biodiesel by acid-catalyzed transformation with previous extraction of the lipids. Alternatively to this process, direct transformation should mean a cost savings for biodiesel production and lipid extraction can be increased, as reported previously for Mucor circinelloides (Vicente et al., 2009).

\section{Conclusions}

It was identified in the biomass of Schizochytrium sp. 24 classes of volatile compounds including $n$-alkanes, 1-alkenes, 1-alkanols, saturated and unsaturated free fatty acids, saturated and unsaturated methyl and ethyl esters of fatty acids, saturated triglycerides and diglycerides, unsaturated monoglycerides, wax esters, sterols, triterpenes, and mono- and sesquiterpenes. Considering the biomass oil extraction (9.47-15.77\%) it was concluded that this organism can be used for industrial production of biodiesel once that the "fully saturated ethyl biodiesel" obtained experimentally gave yields of $41.6 \% \mathrm{w} / \mathrm{w}$ regarding the crude extract, with an average chain length of 15.52 carbons. 


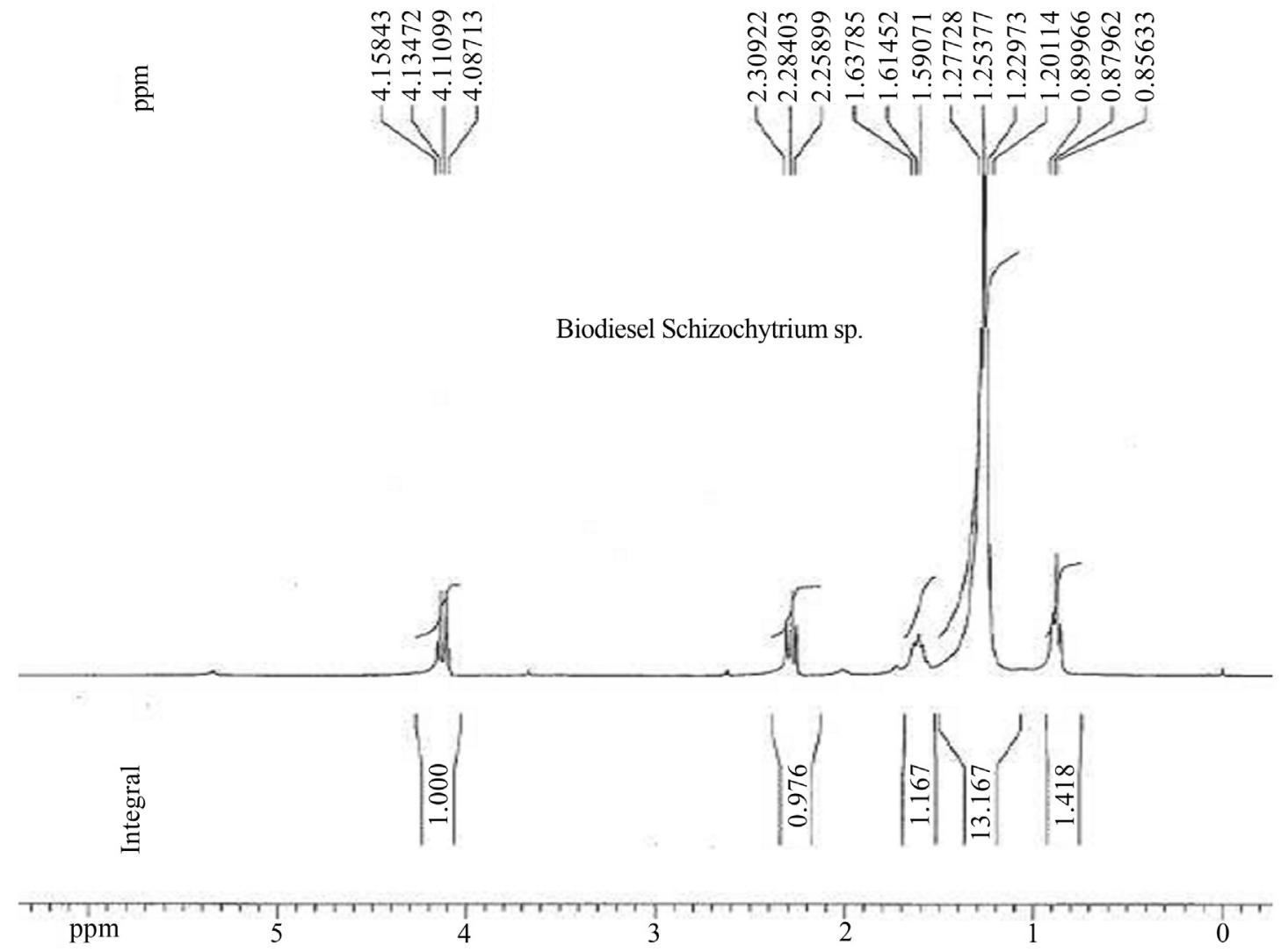

Figure 3 - ${ }^{1} \mathrm{H}-\mathrm{NMR}$ spectrum of saturated ethylic biodiesel obtained from Schizochytrium sp.

\section{Acknowledgments}

The authors would like to thank the CAPES agency, Brasília/ Brazil for the PhD doctoral fellowship and to the European Commission for a Marie Curie Training Site Fellowship, both granted to R.M. Grateful acknowledgement is made for financial support to the project SI-697 (ULPAPD-08/01-5) granted by the Canarian government (Agencia Canaria de Investigación, Innovación y Sociedad de la Información, ACIISI).

\section{References}

Andersson, BA (1978) Mass spectrometry of fatty acid pyrrolidides. Prog Chem Fats Lipids 16:279-308.

Ashford A, Barclay WR, Weaver CA, Giddings TH, Zeller S (2000) Electron microscopy may reveal structure of docosahexaenoic acid-rich oil within Schizochytrium sp. Lipids 35:1377-1386.

Barclay WR. (1994) Process for growing Thraustochytrium and Schizochytrium using non-chloride salts to produce a micro-floral biomass having omega-3 highly unsaturated fatty acids. U.S Pat. 5:340-742.

Barclay WR, Meager KM, Abril JR (1994) Heterotrophic production of long chain omega- 3 fatty acids utilizing algae and algae-like microorganisms. J Appl Phycology 6:123-129.

Barclay WR, Zeller S (1996) Nutritional enhancement of n-3 and n-6 fatty acids in rotifers and Artemia nauplii by feeding spray-dried Schizochytrium sp. J World Aquac Soc 27:314-322.

Bondioli P, Della Bella L, Ravasio N, Zaccheria F (2008) A process for the production of biodiesel from non-conventional sources. In: Prunier, M.L. (ed). Catalysis of organic reactions: twenty-second conference. CRC Press Inc., New York, USA, pp 271-278.

Bowles RD, Hunt AE, Bremer GB, Duchars MG, Eaton RA (1999) Long chain n-polyunsaturated fatty acid production by members of the marine protistan group the thraustochytrids: screening of isolates and optimisation of docosahexaenoic acid production. J Biotech 70:193-202.

Carballeira NM, Miranda C, Lozano CM, Nechev JT, Ivanova A, Ilieva M, Tzvetkova I, Stefanov K (2001) Characterization of novel methyl-branched chain fatty acids from a halophilic Bacillus species. J Nat Prod 64:256-259.

Johnson DT, Takoni KA (2007) The glycerine glut: options for value-added conversion of crude glycerol resulting from biodiesel production. Environm Prog 26:338-348.

Kaneda T (1991) Iso- and anteiso-fatty acids in bacteria: biosynthesis, function, and taxonomic significance. Microbiol Reviews 55:288-302.

Kendrick A, Ratledge C (1992) Lipids of selected molds grown for production of n-3 and n-6 polyunsaturated fatty acids. Lipids 27:15-20.

Kupchan SM, Briton RW, Ziegler MF, Siegel CW (1973) Bruceatin, a new potent antileukemic simaroubolide from Brucea antidysenterica. J Org Chem 38:178-179. 
Lewis TE, Nichols PD, McMeekin TA (1999) The biotechnological potential of thrautochytrids. Mar Biotechnol 1:580-587.

Lewis TE, Nichols PD, McMeekin TA (2000) Evaluation of extraction methods for recovery of fatty acids from lipid-producing microheterotrophs. J Microb Methods 43:107-116.

Nechev J, Christie WW, Robaina R, de Diego FM, Ivanova A, Popov S, Stefanov K (2002) Chemical composition of the sponge Chondrosia reniformis from the Canary Islands. Hydrobiologia 489:91-98.

Nichols D, Bowman J, Sanderson K, Nichols CM, Lewis T, McMeekin T, Nichols PD (1999) Developments with Antarctic microorganisms: culture collections, bioactivity screening, taxonomy, PUFA production and cold-adapted enzymes. Curr Opin Biotech 10:240-246.

Nigam PS, Singh A (2011) Production of liquid biofuels from renewable resources. Prog Energy Comb Sci 37:52-68.

Ochoa-Estopiera A, Lesage J, Gorret N, Guillouet SE (2011) Kinetic analysis of a Saccharomyces cerevisiae strain adapted for improved growth on glycerol: Implications for the development of yeast bioprocesses on glycerol. Biores Technol 102:1521-1527.

Porter D (1990) Phylum Labyrinthulomycota. In: Margulis, L., Corliss, J.O., Melkonian, M., Chapman, D.J. (eds). Handbook of Protoctista, Jones \& Bartlett Publishers, Boston, USA, pp 388-398.
Seyama Y, Otsuka H, Kawaguchi A, Yamakawa T (1981) Branched chain fatty acids in phospholipids of Guinea pig Harderian gland. J Biochem 94:1231-1239.

Vicente G, Bautista LF, Rodríguez R, Gutiérrez FJ, Sádaba I, Ruiz-Vázquez RM, Torres-Martínez S, Garre V (2009) Biodiesel production from biomass of an oleaginous fungus. Biochem Eng J 48:22-27.

Wang GYS, Abrell LM, Avelar A, Borgeson BM, Crews P (1998) New hirsutane based sesquiterpenes from salt water cultures of a marine sponge-derived fungus and the terrestrial fungus Coriolus consors. Tetrahedron 54:7335-7342.

Yokochi T, Honda D, Higashihara T, Nakahara T (1998) Optimization of docohexaenoic acid production by Schizochytrium limacinum SR21. App1 Microbiol Biotech 49:72-76.

Yongmanitchai WY, Ward OP (1989) Omega-3 fatty acids: alternative sources of production. Proc Biochem 24:117-125.

Zabeti N, Bonin P, Volkman JK, Guasco S, Rontani JF (2010) Fatty acid composition of bacterial strains associated with living cells of the haptophyte Emiliania huxleyi. Org Geochem 41:627-636.

\section{Supplementary Material}

Figure S1 - Solvent-solvent processing scheme for partitioning of Schizochytrium sp. biomass, adapted from Kupchan (Kupchan et al., 1973).

All the content of the journal, except where otherwise noted, is licensed under a Creative Commons License CC BY-NC. 


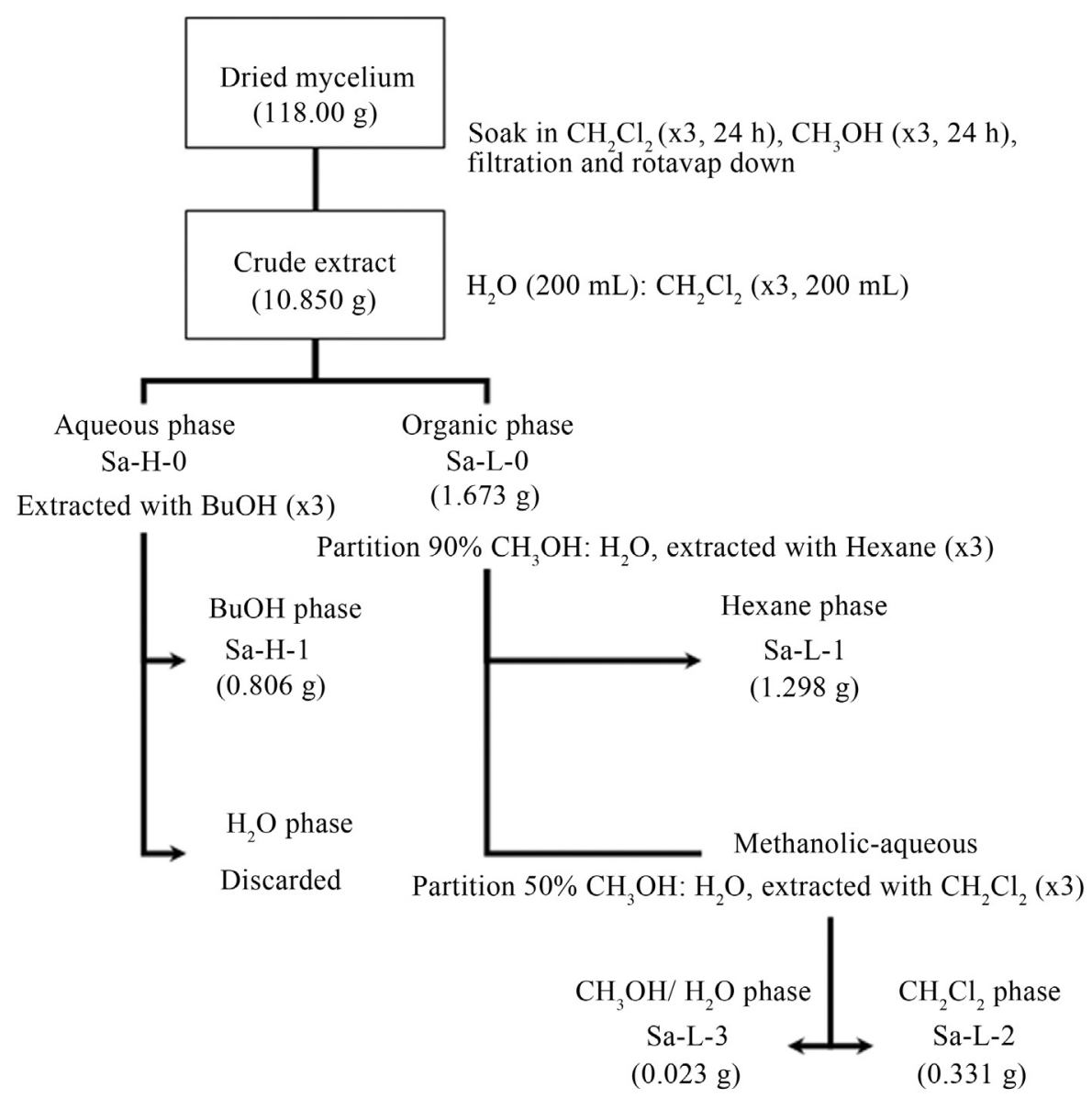

Figure S1 - Solvent-solvent processing scheme for partitioning of Schizochytrium sp biomass, adapted from Kupchan (Kupchan et al., 1973). 